\title{
Effects of geometric non-linearity on energy release rates in a realistic wind turbine blade cross section
}

\author{
Eder, Martin Alexander; Bitsche, Robert; Belloni, Federico
}

Published in:

Composite Structures

Link to article, DOI:

10.1016/j.compstruct.2015.06.050

Publication date:

2015

Document Version

Peer reviewed version

Link back to DTU Orbit

Citation (APA):

Eder, M. A., Bitsche, R., \& Belloni, F. (2015). Effects of geometric non-linearity on energy release rates in a realistic wind turbine blade cross section. Composite Structures, 132, 1075-1084.

https://doi.org/10.1016/j.compstruct.2015.06.050

\section{General rights}

Copyright and moral rights for the publications made accessible in the public portal are retained by the authors and/or other copyright owners and it is a condition of accessing publications that users recognise and abide by the legal requirements associated with these rights.

- Users may download and print one copy of any publication from the public portal for the purpose of private study or research.

- You may not further distribute the material or use it for any profit-making activity or commercial gain

- You may freely distribute the URL identifying the publication in the public portal 


\section{Accepted Manuscript}

Effects of geometric non-linearity on energy release rates in a realistic wind turbine blade cross section

M.A. Eder, R.D. Bitsche, F. Belloni

PII:

S0263-8223(15)00514-0

DOI:

http://dx.doi.org/10.1016/j.compstruct.2015.06.050

Reference:

COST 6549

To appear in:

\section{Composite Structures}

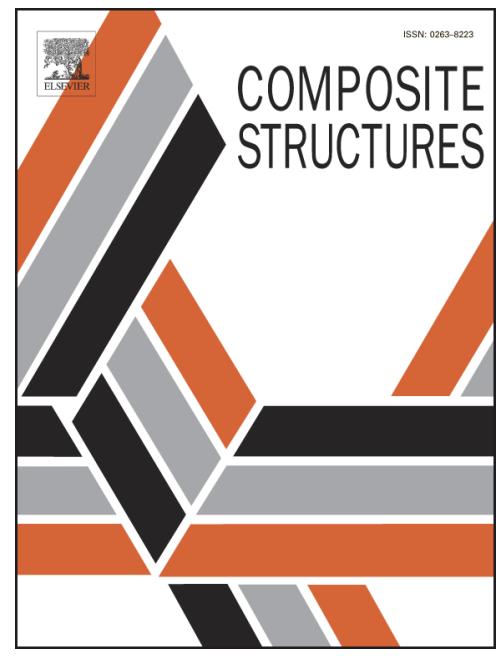

Received Date: $\quad 15$ June 2015

Accepted Date: $\quad 25$ June 2015

Please cite this article as: Eder, M.A., Bitsche, R.D., Belloni, F., Effects of geometric non-linearity on energy release rates in a realistic wind turbine blade cross section, Composite Structures (2015), doi: http://dx.doi.org/10.1016/ j.compstruct.2015.06.050

This is a PDF file of an unedited manuscript that has been accepted for publication. As a service to our customers we are providing this early version of the manuscript. The manuscript will undergo copyediting, typesetting, and review of the resulting proof before it is published in its final form. Please note that during the production process errors may be discovered which could affect the content, and all legal disclaimers that apply to the journal pertain. 


\title{
Effects of geometric non-linearity on energy release rates in a realistic wind turbine blade cross section
}

\author{
M.A. Eder*, R.D. Bitsche, F. Belloni \\ Technical University of Denmark, Department of Wind Energy, Frederiksborgvej 399, \\ 4000 Roskilde, Denmark
}

\begin{abstract}
Most wind turbine rotor blades comprise several adhesively connected subcomponents typically made from glass fibre reinforced polymer composite materials. It is a well-known fact that wind turbine blades are prone to fail in their adhesive joints. However, owing to the complexity of their structural behaviour, little is known about the root causes of adhesive joint failure. This paper investigates the effects of geometrical non-linearity on energy release rates (ERRs) of transversely oriented cracks present in the adhesive joints of a wind turbine rotor blade. Utilising a computationally efficient numerical slice modelling approach, the Virtual Crack Closure Technique (VCCT) is used to compute Mode-I and Mode-II ERRs induced by bi-axial bending. Generic critical loading directions are identified; these may have far-reaching consequences for blade design, analysis and testing.
\end{abstract}

Keywords: Wind turbine blade, adhesive joints, geometric non-linearity, Virtual Crack Closure Technique (VCCT), energy release rate

\section{Introduction}

From a structural mechanics perspective, wind turbine rotor blades are thin-walled, multi-cellular, glass fibre reinforced cantilever beams. The aerodynamic requirements of a wind turbine rotor blade dictates a complex surface geometry, including taper and twist. Glass fibre reinforced polymers usually serve as the main structural material because of their high specific

\footnotetext{
${ }^{*}$ Corresponding author, Mobile: +4521798834 , Email address: maed@dtu.dk
} 
strength, relatively low cost and shapeability. The anisotropy of these materials contributes to the complexity of the structural behaviour. Additionally, the loads experienced by the blades are governed by the complex dynamic, aero-elastic behavior of wind turbines. Finally, wind turbine blades deform extensively, with tip displacements reaching up to $20 \%$ of the blade length. As a consequence, geometrically non-linear effects must often be considered. All factors named above - complex geometry, anisotropic material behavior, complex loading and geometrical non-linearity - contribute to the complex structural response of wind turbine blades.

Wind turbine blades usually consist of several separately manufactured sub-components which are joined adhesively during assembly. Mere empiricism based on proprietary inspection reports and wind turbine blade damage documentations such as Ataya and Ahmed [1] show a high probability of adhesive joint failure - some earlier than expected. According to an NREL report [2], the contribution to the total downtime of wind turbines due to rotor issues ranges from $8 \%$ to $20 \%$. The considerable costs arising from repair or replacement of blades emphasises a strong need for research on mitigation of adhesive joint failure in order to increase blade lifetime. Therefore, fracture analysis of adhesive joints in wind turbine rotor blades is an increasingly important aspect of the blade design process.

Although the research demanded by manufacturers and operators is high, literature, on the other hand is quite tacit about damage investigation of adhesive joints in blades in general, and practically non-existent for a realistic lifetime prediction. The reasons for this lack of knowledge are manifold and not solely attributed to the aforementioned structural complexity. An additional reason for this knowledge gap is due to manufacturing techniques and quality of production; these influence the likelihood of flaws, imperfections, tolerances, residual stresses that occur during curing and so forth. These factors, to name only a few, are known to have considerable impact on the fracture behaviour of adhesive joints but are hard to evaluate during the design process.

In principle, full 3D finite element models are able to capture the complex structural behavior of wind turbine blades to a large extent. However, these models reflect a dilemma caused by the limits set by computational efficiency in conjunction with the high mesh discretization levels (i.e. large number of degrees of freedom) demanded by fracture analysis. Although literature provides various advanced numerical fracture analysis tools for composite materials such as cohesive zone modelling, such models - when applied to full 3D 
blade models - are computationally extremely expensive. As a consequence such models are hardly used outside academia.

To date, three different approaches are used to circumvent the computational limitations that appear in fracture analysis of large complex structures: The sub-modelling technique, the semi-analytical method and cross-sectional analysis.

In the sub-modelling approach, a small part of the structure (the submodel) is modelled with high mesh resolution, while the global model uses a much coarser mesh. The solution of the global model is then interpolated onto the boundary of the sub-model. Fracture analysis is subsequently conducted on the sub-model as demonstrated and discussed by Haselbach [3] and Haselbach et al. [4].

In the semi-analytical approach, nodal forces in the vicinity of the adhesive connections are obtained from 3D models with a low degree of modelling detail and low mesh resolution. Subsequently, these forces are applied to analytical fracture models which resemble the actual joint geometry in the blade. A practical application of this method on adhesive joints in wind turbine blades was presented by Corre [5].

In the cross-sectional analysis approach only a thin cross sectional slice with a high level of detail and mesh resolution is modelled. The designation thin means that the thickness is small in comparison to the cross-section dimensions. The theoretical basis of the cross-section slice approach used to study ovalisation effects of thin-walled tubular cross sections originates with Kármán [6] and later Brazier [7]. Checchini and Weaver [8] were the first to numerically analyse a symmetric multi-cellular cross-section slice of a wind turbine blade. In the slice approach, displacement and force boundary constraints are applied to the cross-sectional faces such that the conditions of beam theory for the prevailing bending load case are satisfied.

Clearly, all three methods have drawbacks along with their advantages. The cross-section slice approach was found to be most suitable for investigation of geometric non-linearity affecting adhesive joints in a generic wind turbine cross section. Therefore, the pros and cons of its application will be briefly discussed. The striking advantage of the cross-section slice approach is a high mesh discretization level and level of detail without compromising computational efficiency. Changes of geometry are less cumbersome when compared to 3D models. Both geometric non-linearity and material nonlinearity can be evaluated. Furthermore, this approach lends itself to the application of advanced fracture analyses tools for crack propagation analy- 
sis such as cohesive zone modelling and other methods as treated by Riccio [9].

The disadvantage of the cross-section slice approach is that local buckling effects (e.g. wave formation along the trailing edge) or effects arising from taper and twist of the blade are disregarded. Moreover, cracks are assumed to be transversely orientated where the crack front length must be assumed to be in the order of the blade length. Local effects of cracks with a short front length cannot be captured, as the stiffening effect from neighbouring un-cracked cross sections is disregarded.

The following influenced the investigations performed in this paper: It was known from both experimental blade research and from numerical analyses $[10,11]$ that blades that naturally undergo large deformations experience geometrically non-linear in-plane warping deformations that might be responsible for adhesive joint failure. An analytical investigation of geometrically non-linear effects on a simple cross-section as discussed in [12] supports this suspicion. These investigations suggest that of all six cross-section forces, bi-axial bending (i.e. $M_{x}$ and $M_{y}$ ) is the main contributor to Mode-I and Mode-II ERRs in trailing edge cracks - provided that local buckling is suspended. This paper consequently seeks to corroborate these analytical findings numerically on a realistic wind turbine blade cross section. The adopted slice approach served the aim of this paper to scrutinise the effects of geometric non-linearity on the energy release rates (ERRs) in transversely orientated pre-cracks present in all main adhesive joints of a generic wind turbine cross section. Note that it was not within the scope of this paper to conduct crack growth analyses but rather to use ERRs as indicator, giving insight into generic structural non-linear warping behaviour and its effect on adhesive joints.

For this purpose, a single section located at a radial position of $62.39 \mathrm{~m}$ of the DTU Wind Energy 10MW light rotor reference wind turbine blade was chosen. A detailed description of the blade appears in Bak et al. [13, 14]. The adhesive joints were modelled with a high degree of detail, typical of classic blade design approaches. Fracture analysis was conducted on the trailing edge joint, the leading edge joint as well as on the four cap joints. Due to similarities in behaviour the results of only four key-joints (see Fig. 1) are presented.

The Virtual Crack Closure Technique (VCCT) was used to compute bendinginduced ERRs in cracks that were introduced in the adhesive of six joints. Based on the obtained results, critical loading directions and generic in-plane 
cross-section deformation behaviour is deduced and subsequently discussed. The paper concludes with a summary of findings which facilitate fracture analysis of adhesive joints in wind turbine blades, that might lead to improved blade designs.

\section{Calculation}

\subsection{Slice model}

The DTU Wind Energy 10 MW light rotor reference blade is $86.366 \mathrm{~m}$ long and made of glass fibre reinforced composites; balsa wood is used as the sandwich core. The properties of the composite materials (Uniax, Biax and Triax) listed in Tab. 1 are typical for the multi-directional plies.

Table 1: Engineering constants of the orthotropic GFRP materials, the sandwich core material and the isotropic adhesive. The indices 1,2,3 are referring to the local material orientations where direction-1 is parallel to the spanwise direction of the blade and direction-3 denotes the local through-thickness direction.

\begin{tabular}{ccccccc}
\hline Property & Uniax & Biax & Triax & Balsa & Adhesive & Unit \\
\hline Elast. modulus $E_{11}$ & $4.163 \times 10^{10}$ & $1.392 \times 10^{10}$ & $2.179 \times 10^{10}$ & $5.000 \times 10^{7}$ & $3.500 \times 10^{9}$ & $\mathrm{~N} \mathrm{~m}^{-2}$ \\
Elast. modulus $E_{22}$ & $1.493 \times 10^{10}$ & $1.392 \times 10^{10}$ & $1.467 \times 10^{10}$ & $5.000 \times 10^{7}$ & $3.500 \times 10^{9}$ & $\mathrm{~N} \mathrm{~m}^{-2}$ \\
Elast. modulus $E_{33}$ & $1.342 \times 10^{10}$ & $1.210 \times 10^{10}$ & $1.210 \times 10^{10}$ & $2.730 \times 10^{9}$ & $3.500 \times 10^{9}$ & $\mathrm{~N} \mathrm{~m}^{-2}$ \\
Poisson's ratio $\nu_{12}$ & 0.241 & 0.533 & 0.478 & 0.500 & 0.360 & - \\
Poisson's ratio $\nu_{13}$ & 0.268 & 0.275 & 0.275 & 0.013 & 0.360 & - \\
Poisson's ratio $\nu_{23}$ & 0.330 & 0.333 & 0.333 & 0.013 & 0.360 & - \\
Shear modulus $G_{12}$ & $5.047 \times 10^{9}$ & $1.150 \times 10^{10}$ & $9.413 \times 10^{9}$ & $1.667 \times 10^{7}$ & $1.287 \times 10^{9}$ & $\mathrm{~N} \mathrm{~m}^{-2}$ \\
Shear modulus $G_{13}$ & $5.047 \times 10^{9}$ & $4.539 \times 10^{9}$ & $4.538 \times 10^{9}$ & $1.500 \times 10^{8}$ & $1.287 \times 10^{9}$ & $\mathrm{~N} \mathrm{~m}^{-2}$ \\
Shear modulus $G_{23}$ & $5.047 \times 10^{9}$ & $4.539 \times 10^{9}$ & $4.538 \times 10^{9}$ & $1.500 \times 10^{8}$ & $1.287 \times 10^{9}$ & $\mathrm{~N} \mathrm{~m}^{-2}$ \\
Mass density $\rho$ & $1.916 \times 10^{3}$ & $1.845 \times 10^{3}$ & $1.845 \times 10^{3}$ & $1.100 \times 10^{2}$ & $1.350 \times 10^{3}$ & $\mathrm{~kg} \mathrm{~m}^{-3}$ \\
\hline
\end{tabular}

The blade design follows a classic approach where a load-carrying box girder is formed by two shear webs and two caps. The aero-dynamic shell is formed by a pair of trailing panels and a pair of leading panels - both attached to the main spar. The cross section at a radial position of $62.39 \mathrm{~m}$ was chosen for fracture analysis. The third shear web present in the original design adjacent to the trailing edge joint was removed. Additional uniaxial layers were used at the trailing edge to increase the local buckling resistance. This cross-section was specifically chosen from a region where the influence of taper between neighbouring cross-sections is negligibly small. The selected 
cross-section had a chord length of $c=3.674 \mathrm{~m}$ and a maximum height of $h$ $=0.880 \mathrm{~m}$ with a cap width of $a=0.545 \mathrm{~m}$ as shown in Fig.1. A slice model

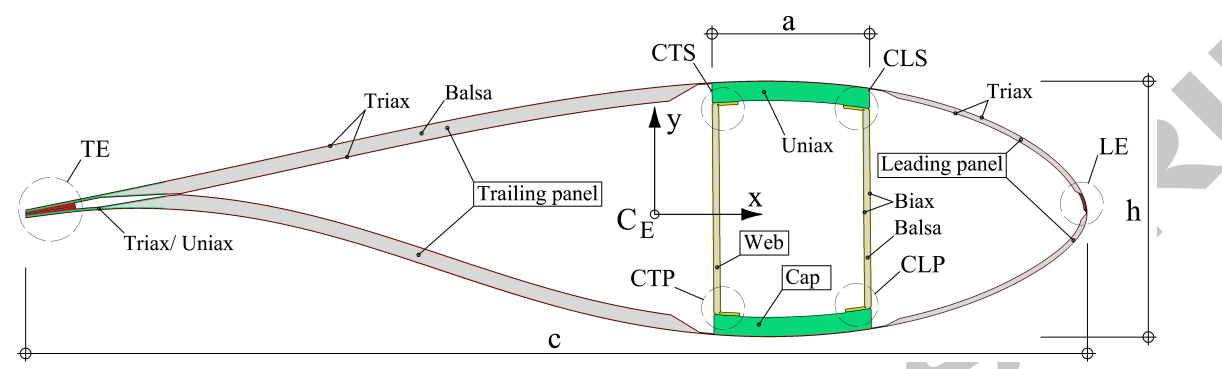

Figure 1: Cross section at $62.39 \mathrm{~m}$ showing main structural parts and the associated material assignments and global coordinate system with origin at elastic centre. Six typical adhesive joints with location denoted as trailingedge (TE), cap-trailing-suction (CTS), cap-leading-suction (CLS), leadingedge (LE), cap-leading-pressure (CLP) and cap-trailing-pressure (CTP) were modelled.

was created by first building a $2 \mathrm{D}$ mesh and then extruding the $2 \mathrm{D}$ mesh into a single layer of 3D continuum elements with a thickness of $t=8.0 \times 10^{-3} \mathrm{~m}$. The commercial finite element package Abaqus [15] was used for numerical fracture analysis. The model was discretized by $9 \times 10^{3}$ enriched eight-noded solid elements (Abaqus element type C3D8I) with a total of $7.6 \times 10^{4}$ nodes.

The slice model was analysed for two different model configurations where configuration- $T$ was used for the torsion load case and configuration- $B$ was used for bi-axial bending load cases, as will be subsequently discussed. A torsional moment $M t_{B}$ per unit-length - in this paper referred to as Brazier torsion - is introduced into the cross section if the bending axis is not aligned with one of the principal bending axes as discussed in [12]. Equation 1 expresses the magnitude of the Brazier torsion as a function of bending moment for a force-controlled analysis. Equation 2 gives the same as function of bending curvature for a displacement controlled analysis.

$$
\begin{aligned}
M t_{B} & =\frac{\left(\left(M_{x}^{2}-M_{y}^{2}\right) E I_{x y}-M_{x} M_{y}\left(E I_{x x}-E I_{y y}\right)\right) t}{E I_{x x} E I_{y y}-E I_{x y}^{2}} \\
M t_{B} & =\left(\kappa_{x}^{2}+\kappa_{y}^{2}\right)\left(\sin \alpha \cos \alpha\left(E I_{y y}-E I_{x x}\right)+\left(2 \cos \alpha^{2}-1\right) E I_{x y}\right) t
\end{aligned}
$$


where $\alpha$ is the angle of the rotation vector (bending axis) in a polar coordinate system counterclockwise positive, $M_{x}$ and $M_{y}$ are the cross-sectional bending moments around the global x-axis and y-axis, respectively, $E I_{x x}$ and $E I_{y y}$ are the bending stiffness around the x-axis and y-axis respectively, $E I_{x y}$ represents the deviatoric bending stiffness, $\kappa_{x}$ represents the curvature around the $\mathrm{x}$-axis and $\kappa_{y}$ represents the curvature around the $\mathrm{y}$-axis. The boundary conditions BC1 and BC2 (Tab. 2) have one purpose: to prevent rigid body motion. The reaction forces of these boundary conditions are induced by Brazier torsion; such reaction forces must be zero. Therefore, the slice model was analysed in two stages:

- stage one: a unit-torsion was applied to model configuaration- $\mathrm{T}$ in order to obtain the reaction forces at the back surface using a linear perturbation analysis.

- stage two: these reaction forces were applied as concentrated nodal forces to model configuration-B. Equation 2 was used to scale these forces such that the net torsional moment vanished in every increment and for every loading direction.

A static implicit solver technique was used for fracture analysis of configuration$\mathrm{B}$ where geometric non-linearity was introduced by equilibrium on the deformed structure.

The following paragraph sheds some light on the choice of boundary conditions for configuration- $T$ and subsequently for configuraton-B. In case of isotropic material behaviour, the adopted boundary conditions of configurationT satisfy the St. Venant torsion principle which states that the in-plane deformations under pure torsion are zero. This principle does not hold in the event of orthotropic material behaviour, as will be subsequently discussed. The rotation of the orthotropic elasticity tensor $C_{p q r s}$ around the local Zdirection gives the transformed tensor according to $C_{i j k l}=n_{i p} n_{j q} n_{k r} n_{l s} C_{p q r s}$ where the expressions denoted with $n$ are the cosines of the angle enclosed by the basis vectors as discussed by Mang and Hofstetter [16]. Figure 2 depicts a small cross-section wall element whose 1-2 material axes are skewed to the cross-section coordinate system. The constitutive equations $\epsilon_{i j}=S_{i j k l} \sigma_{k l}$ with the compliance tensor $S_{i j k l}=C_{i j k l}^{-1}$ show that if all components of $\sigma_{k l}$ except $\sigma_{x z}$ are zero then $\epsilon_{22}$ and $\epsilon_{33} \neq 0$. Therefore, the in-plane warping deformations do not - strictly speaking - comply with the adopted boundary conditions for torsion. However, configuration- $\mathrm{T}$ is based on the assumption 


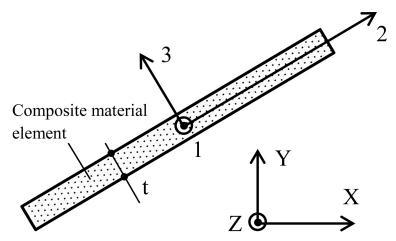

Figure 2: Shear stress coupling of orthotropic material with the material coordinate system being misaligned with cross-section coordinate system.

that the in-plane warping deformations of the cross section of the present material properties subject to torsion are small for small rotations as the degree of anisotropy is mild. In other words, restraining in-plane deformations have a negligibly small effect on torsional shear stresses $\sigma_{12}$.

Configuration-B assumes that out-of-plane warping deformations of the cross-section subject to bending are zero. Figure 3 shows the loads and boundary conditions as applied in the $\mathrm{x}-\mathrm{y}$-plane as well as in the $\mathrm{y}$-z-plane. A kinematic (rigid) coupling constraint was applied to the nodes of the front surface which was coupled to a master node located in the elastic centre of the cross section. The model was loaded at the master node through application of rotations $\theta_{x}$ and $\theta_{y}$ in configuration-B or by a concentrated torsional moment $M_{z}$ in configuration-T.

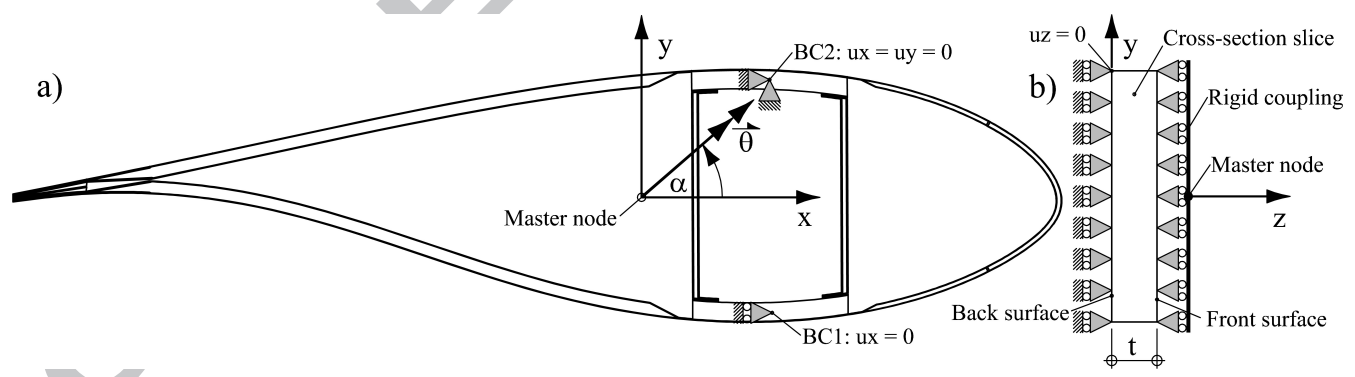

Figure 3: a) Rotation vector $\vec{\theta}$ and its direction angle $\alpha$ applied at master node and in-plane boundary conditions $\mathrm{BC} 1$ and $\mathrm{BC} 2$ for prevention of rigid body motions; b) Out-of-plane boundary conditions applied to the back surface of the cross-section slice with rigid coupling constraints applied to the front surface for configuration-B.

Table 2 lists the boundary conditions that were applied to the slice model for the two model configurations separately. 
Table 2: Six essential boundary conditions for two different model configurations: configuration- $\mathrm{T}$ and configuration-B. Hyphen refers to non-existing degrees of freedom. The abbreviations $B C 1$ and $B C 2$ are additional boundary conditions applied in the midpoints of both caps (Fig.3) which prevent rigid body motions but otherwise do not cause reaction forces.

\begin{tabular}{|c|c|c|c|c|c|c|}
\hline Node $(\mathrm{s})$ & $u_{x}$ & $u_{y}$ & $u_{z}$ & $u r_{x}$ & $u r_{y}$ & $u r_{z}$ \\
\hline Config.-T: back surface & fixed & fixed & free & - & & 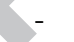 \\
\hline Config.- $T$ : front surface (slave) & fixed & fixed & free & - & & - \\
\hline Config.-T: master node & fixed & fixed & fixed & fixed & fixed & free $^{+}$ \\
\hline Config.-B: back surface & free & free & fixed & - & 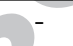 & - \\
\hline Config.-B: front surface (slave) & free & free & fixed & & 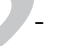 & - \\
\hline Config.-B: master node & fixed & fixed & fixed & & free $^{*}$ & fixed \\
\hline Config.-B: BC1 & fixed & free & free & & - & - \\
\hline Config.-B: BC2 & fixed & fixed & free & & - & - \\
\hline
\end{tabular}

${ }^{+}$prescribed torsional moment; ${ }^{*}$ prescribed rotations.

The three elastic bending stiffness properties of the cross section can be obtained by equation 3 for two different angles of bending $\alpha$. For this purpose a linear perturbation analysis of the slice model (configuration-B) was performed, where a pure flap-wise and a pure edge-wise rotation was applied in the elastic centre of the cross section. The position of the elastic centre was obtained by the cross-section analysis tool BECAS developed by Blasques [17]. The following expression holds for small rotations $\kappa=\theta / t$ where $\kappa$ represents the curvature and $\theta$ represents the cross-sectional rotation around the axis of curvature and $t$ represents the slice thickness.

$$
\left(\begin{array}{c}
M_{x} \\
M_{y}
\end{array}\right)=\left[\begin{array}{ll}
E I_{x x} & E I_{x y} \\
E I_{x y} & E I_{y y}
\end{array}\right]\left(\begin{array}{c}
\kappa_{x} \\
\kappa_{y}
\end{array}\right)
$$

where $E I_{x x}$ and $E I_{y y}$ are the bending stiffness around the $\mathrm{x}$-axis and $\mathrm{y}$ axis respectively, $E I_{x y}$ represents the deviatoric bending stiffness, $\kappa_{x}$ and $\kappa_{y}$ represent the curvature around the $\mathrm{x}$-axis and $\mathrm{y}$-axis respectively.

Table 3 lists the elastic bending stiffness properties in the global coordinate system with its origin in the elastic centre as shown in Fig. 1. 
Table 3: Numerically obtained elastic bending stiffness properties of the slice, with $\varphi$ being the orientation of the principal axis with respect to the elastic centre.

\begin{tabular}{ccc}
\hline Property & Value & Unit \\
\hline$E I_{x x}$ & $5.42335 \times 10^{8}$ & $\mathrm{~N} \mathrm{~m}^{2}$ \\
$E I_{y y}$ & $2.58351 \times 10^{9}$ & $\mathrm{~N} \mathrm{~m}^{2}$ \\
$E I_{x y}$ & $3.22238 \times 10^{7}$ & $\mathrm{~N} \mathrm{~m}^{2}$ \\
$\varphi$ & $-9.04185 \times 10^{-1}$ & $\circ$ \\
\hline
\end{tabular}

\subsection{Fracture analysis}

The VCCT tool in Abaqus was used to compute the energy release rates (ERRs) in the tip of the cracks introduced in the adhesive. Within the framework of the VCCT, the ERRs are obtained as the product of the nodal forces at the crack tip and the associated nodal displacements of the crack faces adjacent to the crack tip as shown in Fig. 4. In the present study, only

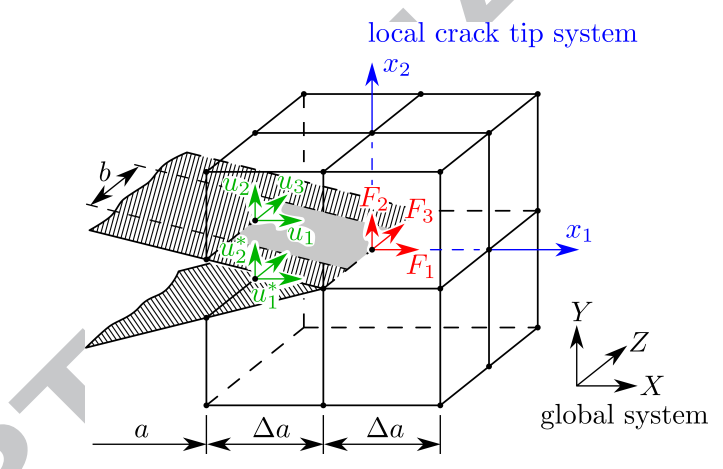

Figure 4: VCCT principle for eight-noded elements showing the required nodal forces (red) and nodal displacements (green) as well as the virtually created crack surface hatched in grey. The nodal forces and displacements are defined in a local crack coordinate system which follows the rigid body motion during loading.

Mode-I and Mode-II ERRs $G_{I}$ and $G_{I I}$ were of interest. These values can numerically be obtained with equations 4 and 5 as depicted in Fig. 4.

$$
\begin{aligned}
& G_{I}=\frac{1}{2 b \Delta a} F_{2} \Delta u_{2} \\
& G_{I I}=\frac{1}{2 b \Delta a} F_{1} \Delta u_{1}
\end{aligned}
$$


where $F_{1,2}$ represents the nodal forces at the crack tip in direction $x_{1,2}, \Delta u_{1,2}$ represents the relative nodal displacements behind the crack tip, $b$ denotes the proportional element width and $\Delta a$ denotes the element length next to the crack tip.

A detailed description of the VCCT and its application in computational fracture mechanics for various element sizes and types appears in Krueger [18]. In order to avoid material interpenetration, hard, frictionless node-tosurface contact conditions were assigned to the crack faces. The VCCT was only used to compare ERRs where crack growth was not modelled.

The fracture interaction law proposed by Kenane and Benzegagh [19] - given by equation 6 - was used to obtain the joint-specific critical loading directions and will be discussed in Section 3 .

$$
G_{e q}=G_{I c}+\left(G_{I I c}-G_{I c}\right)\left(\frac{G_{I I}}{G_{I}+G_{I I}}\right)^{\eta}
$$

where $G_{I c}$ and $G_{I I c}$ are the critical Mode-I and Mode-II energy release rates and $\eta$ is an empirically obtained dimensionless exponent. The corresponding Mode-I and Mode-II stress intensity factors $K_{I}$ and $K_{I I}$ and the in-plane phase angle $\psi_{0}[\mathrm{rad}]$ can be computed as follows:

$$
\begin{aligned}
K_{I} & =\sqrt{\frac{G_{I} E}{1-\nu^{2}}} \\
K_{I I} & =\sqrt{\frac{G_{I I} E}{1-\nu^{2}}} \\
\psi_{0} & =\arctan \left(\frac{K_{I I}}{K_{I}}\right)
\end{aligned}
$$

where $E$ and $\nu$ are the elastic properties of the adhesive as given in Tab. 1 .

For the sake of simplicity the experimentally obtained values reported in [20] were used. That is, the Mode-I and Mode-II initiation ERRs for Type- $B$ detail in [20, Fig. 5 (b), Tab. 1] with $G_{I c}=600 \mathrm{~J} \mathrm{~m}^{-2}$ and $G_{I I c}=1200 \mathrm{~J} \mathrm{~m}^{-2}$ were used under the assumption that the investigated cracks are small prior to the occurrence of fibre bridging. The exponent $\eta=2$ was chosen for brittle resin according to [19].

Figure 5 shows detailed drawings of the four main joints, namely the trailing edge joint (TE), the suction side cap joint towards trailing edge 
(CTS), the suction side cap joint towards the leading edge (CLS) and the leading edge joint (LE). The cracks were transversely orientated in that the designated propagation direction was perpendicular to the blade axis. The crack lengths were chosen to be short with respect to the bond length in order to examine the assumption of a fairly small macro defect being already present. The crack plane was conservatively located in the centre of the brittle adhesive, thereby avoiding fibre-bridging effects. The goal was to be consistent with linear elastic fracture mechanics required by the VCCT. Moreover, in this way element size dependency of the mode-mixity computed by VCCT of cracks located in bi-material interfaces could be avoided.

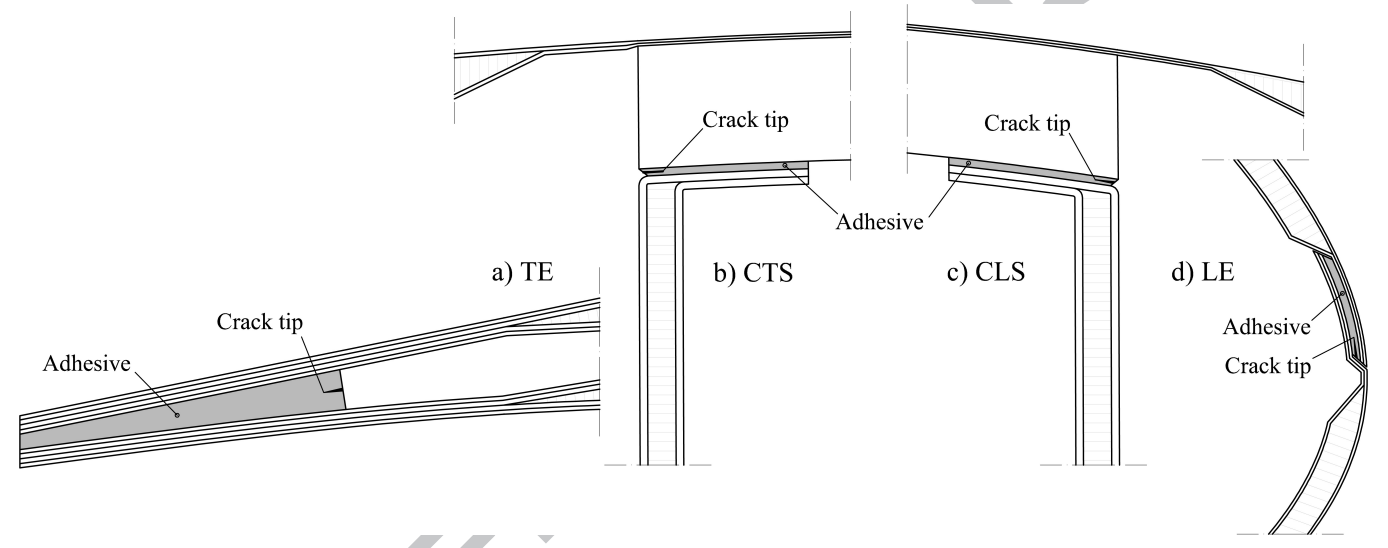

Figure 5: Details of the four main adhesive joints TE, CTS, CLS and LE. Small cracks (black triangles) with a length varying between 10 and $15 \mathrm{~mm}$ were introduced in the centre of the adhesive layers (grey hatch). The adhesive layer inside thickness for the TE-joint is $20 \mathrm{~mm}$; the adhesive thickness of the remaining joints is $4 \mathrm{~mm}$.

\section{Results}

Figure 6 (a) compares the numerically obtained Brazier torsion at the master node with the analytical solution given by equation 2 as a function of curvature. Figure 6 (a) shows that the Brazier torsion increases quadratically with curvature where bending directions $\alpha=0^{\circ}$ and $\alpha=90^{\circ}$ yield low levels of Brazier torsion because the angles are almost aligned with the principal axes. Figure 6 (b) shows the oscillating nature of the Brazier torsion when obtained as a function of the bending direction which is consequently zero at 
$E I_{x y}=0$ and occurs at $\alpha=\varphi+n \pi / 2$ with $n=1,2,3, \ldots$ (see Tab. 3 ). Figure

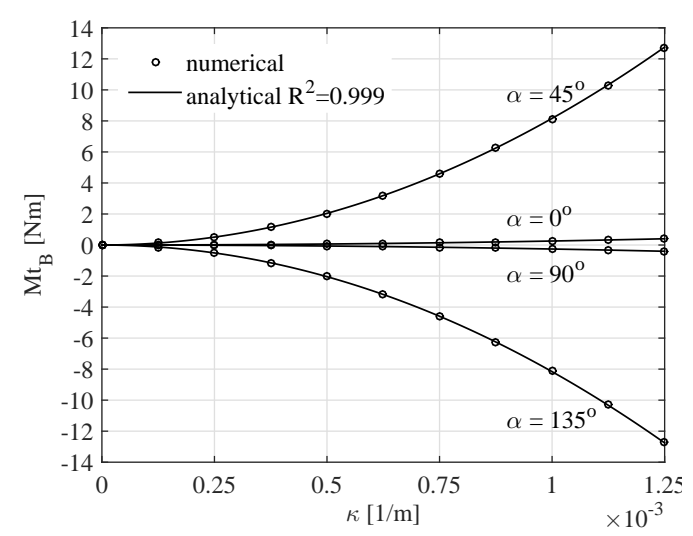

(a)

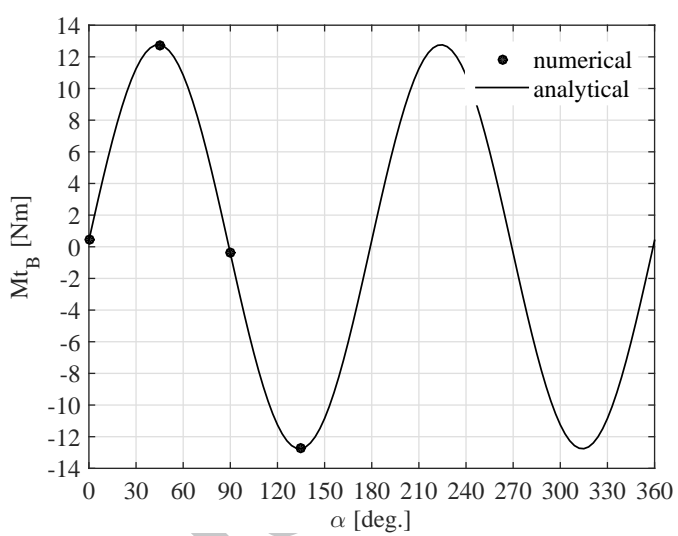

(b)

Figure 6: (a) Brazier torsion as a function of curvature $\kappa$ for different bending directions $\alpha=0^{\circ}$ (pure flap-wise), 45\%, 90 (pure edge-wise), 135 ; (b) Brazier torsion for $\kappa=1.25 \times 10^{-3} \mathrm{~m}^{-1}$ as a function of $\alpha$ where circular markers represent numerical results.

7 shows the Mode-I and Mode-II stress intensity factors $K_{I}$ and $K_{I I}$ (solid black line) of the TE-joint as a function of the bending curvature $\kappa$ and the bending direction $\alpha$. The dotted contour plots represent 35\%,70\%, $105 \%$ and $140 \%$ bending moment isolines of the flap-wise load-carrying capacity $M_{x}^{\max }=8.616 \times 10^{6} \mathrm{Nm}$ as stipulated in [21]. Figure 7 (a) shows two distinct ridges at approx. $135^{\circ}$ and $315^{\circ}$. Figure 7 (b) shows that the angles of the $K_{I I}$ ridges coincide with those of the $K_{I}$ ridges but show additional intermediate ridges every $90^{\circ}$. 


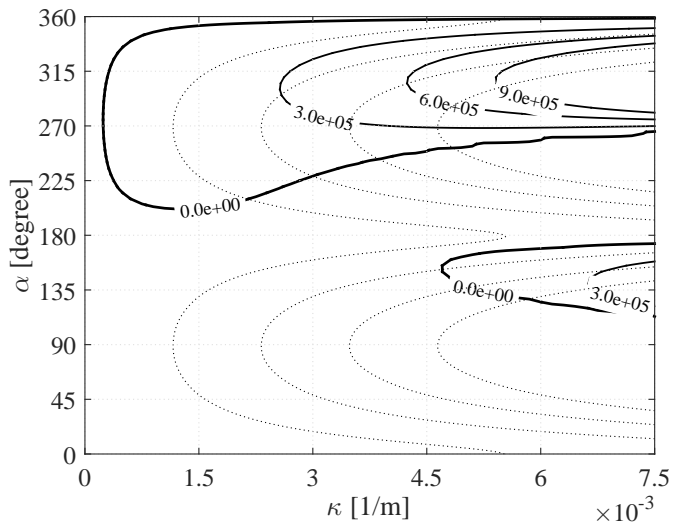

(a) $K_{I}$

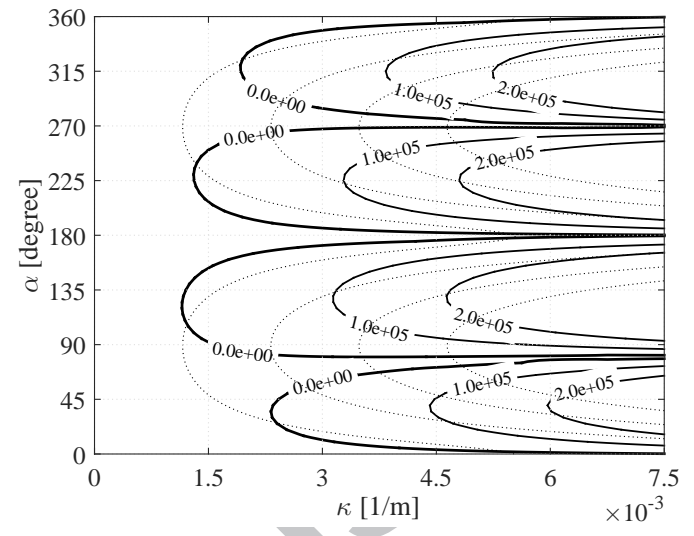

(b) $K_{I I}$

Figure 7: (a) Contour plot of $K_{I}\left[\mathrm{~Pa} \mathrm{~m}^{1 / 2}\right]$ at the TE-joint as a function of curvature $\kappa$ and the angle of the bending axis $\alpha$; (b) Contour plot of $K_{I I}$ $\left[\mathrm{Pa} \mathrm{m}{ }^{1 / 2}\right]$ at the TE-joint as a function of curvature $\kappa$ and the angle of the bending axis $\alpha$.

Figure 8 shows that the $K_{I}$ and the $K_{I I}$ contour plots coincide and that the contours resemble the bending moment isolines. One peculiarity can be seen in Fig. 8 (b) where the $K_{I I}$ contours at approx. $315^{\circ}$ do not form a ridge but rather take the shape of a horseshoe.

The $K_{I}$ and the $K_{I I}$ contour plots of the CTS and CLS cap joints shown in Figs. 9 and 10 are similar to one another. 


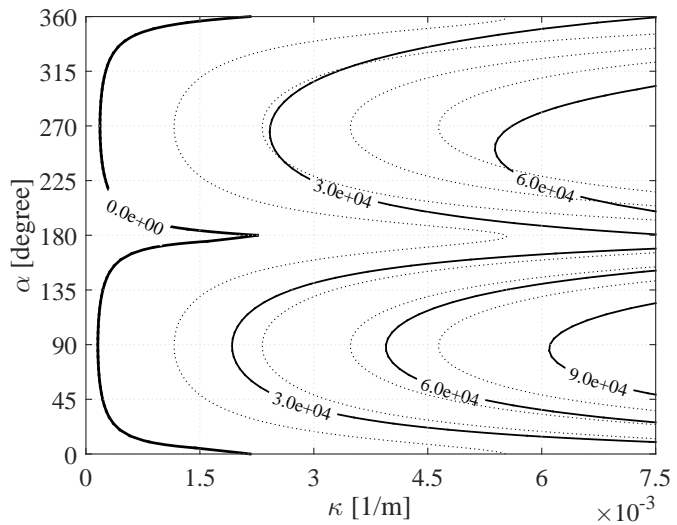

(a)

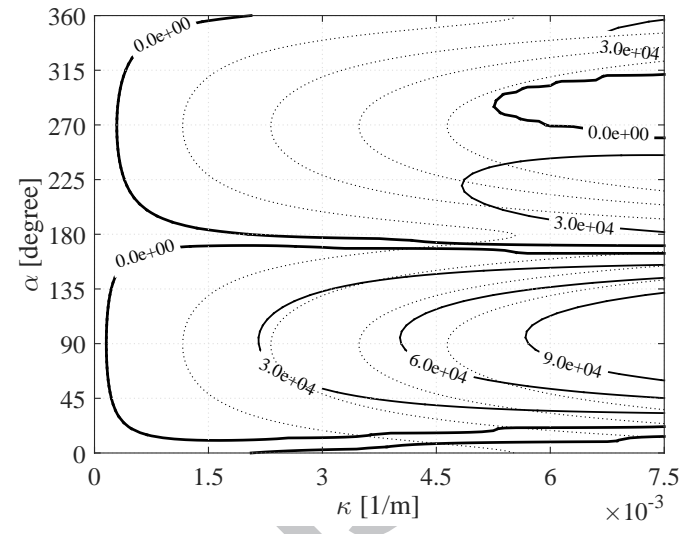

(b)

Figure 8: (a) Contour plot of $K_{I}\left[\mathrm{~Pa} \mathrm{~m}^{1 / 2}\right]$ at the LE-joint as a function of curvature $\kappa$ and the angle of the bending axis $\alpha$; (b) Contour plot of $K_{I I}$ $\left[\mathrm{Pa} \mathrm{m}{ }^{1 / 2}\right]$ at the LE-joint as a function of curvature $\kappa$ and the angle of the bending axis $\alpha$.

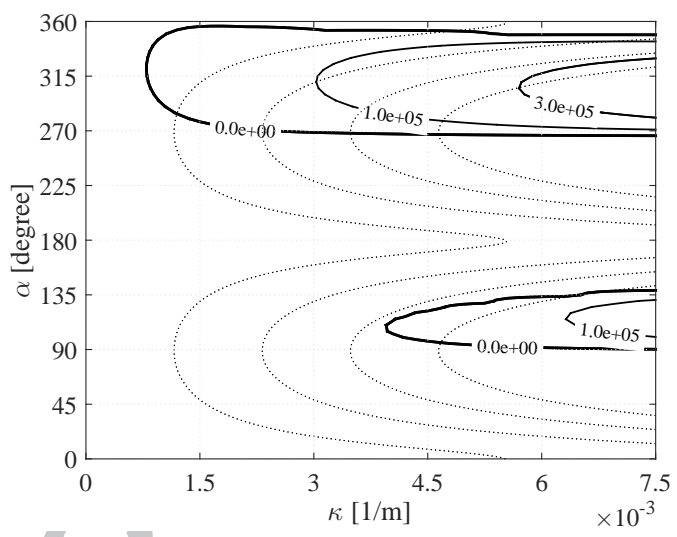

(a)

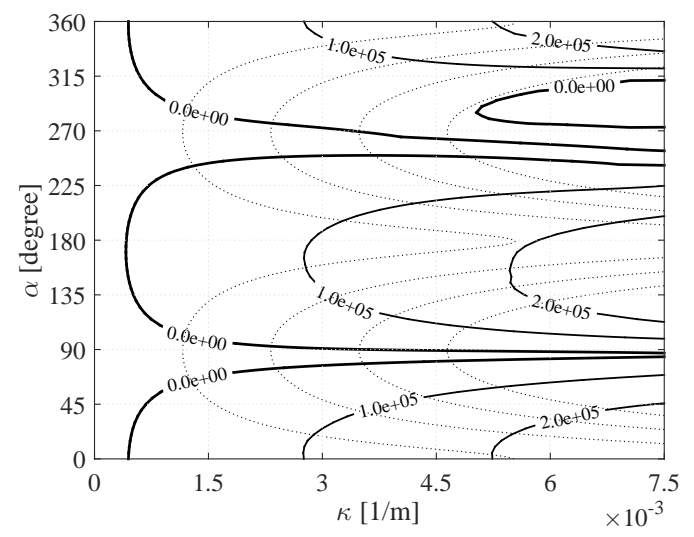

(b)

Figure 9: (a) Contour plot of $K_{I}\left[\mathrm{~Pa} \mathrm{~m}^{1 / 2}\right]$ at the CTS-joint as a function of curvature $\kappa$ and the angle of the bending axis $\alpha$; (b) Contour plot of $K_{I I}$ $\left[\mathrm{Pa} \mathrm{m}{ }^{1 / 2}\right]$ at the CTS-joint as a function of curvature $\kappa$ and the angle of the bending axis $\alpha$.

The $K_{I}$ contours show two peaks whereas the $K_{I I}$ contours show three 
peaks. Moreover, the $K_{I}$ and $K_{I I}$ contours do not coincide as do the TE and LE-joints, which suggests two separate mechanisms.

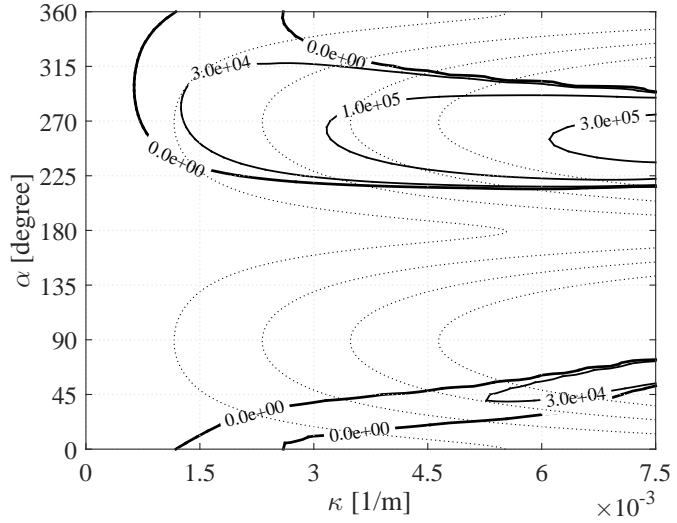

(a)

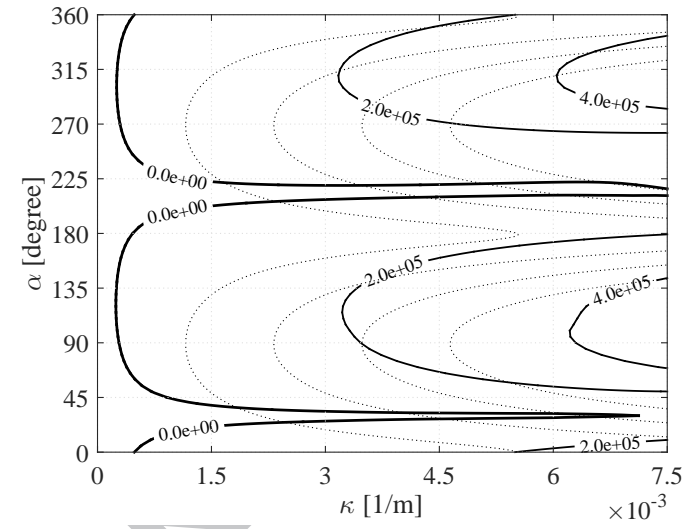

(b)

Figure 10: (a) Contour plot of $K_{I}\left[\mathrm{~Pa} \mathrm{~m}^{1 / 2}\right]$ at the CLS-joint as a function of curvature $\kappa$ and the angle of the bending axis $\alpha$; (b) Contour plot of $K_{I I}$ $\left[\mathrm{Pa} \mathrm{m}{ }^{1 / 2}\right]$ at the CLS-joint as a function of curvature $\kappa$ and the angle of the bending axis $\alpha$.

Figure 11 (a) shows the upscaled warping deformation of the trailing edge panels for $\alpha=315^{\circ}$, indicating a trailing edge opening accompanied by an upwards movement of the edge. Figure 11 (b) shows the upscaled warping deformation of the box-girder for $\alpha=306^{\circ}$, which deforms into a rhomboidal shape. The deformation leads to tensile strains in the outer surface of the left-hand-side shear web when the CLS-joint moves inwards, which induces a Mode-I opening in the CTS-joint. The difference in scaling factors shows that the box-girder exhibits a significantly higher in-plane stiffness compared to the TE-panels. 


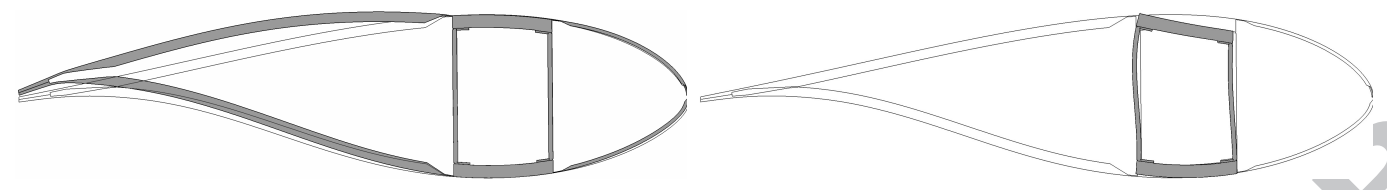

(a)

(b)

Figure 11: (a) Trailing edge panel deformation with a scaling factor of 2 (grey hatch) superimposed on the undeformed cross-section geometry; (b) Box-girder deformation with a scaling factor of 40 (grey hatch) superimposed on the undeformed cross-section geometry.

Figure 12 depicts the normalised ERR contour plots for various joints obtained by equation 6 and show the utilisation levels of the equivalent critical ERR. The TE-joint shows that values close to one can be reached for the $140 \%$ isoline. The utilisation level of the equivalent ERR of both cap joints and the LE-joint is low.

Table 4 lists the most critical angles of the four individual joints separately obtained from Fig. 12 a) through d). The angle $\alpha_{\text {crit }}$ refers to the angular direction of the cross-section rotation vector (bending axis) which yields the highest $G_{t o t} / G_{e q}$ value for sections taken at $\kappa=3 \times 10^{-3} \mathrm{~m}^{-1}$ and $\kappa=6 \times 10^{-3} \mathrm{~m}^{-1}$. Similarly, the angle $\beta_{\text {crit }}=\arctan \left(M_{y} / M_{x}\right)$ refers to the angular direction of the bending moment vector which can be obtained from $\kappa_{x, y}$ using equation 3.

Table 4: Critical angle ranges of bending axis $\alpha_{\text {crit }}$ and critical bending moment vector angle $\beta_{\text {crit }}$.

\begin{tabular}{cccccc}
\hline Angle & TE & LE & CTS & CLS & Unit \\
\hline$\alpha_{\text {crit }}$ & $303-309$ & $90-92$ & $302-315$ & $257-294$ & [degree] \\
$\beta_{\text {crit }}$ & $277-279$ & $89-90$ & $276-281$ & $266-274$ & [degree] \\
\hline
\end{tabular}




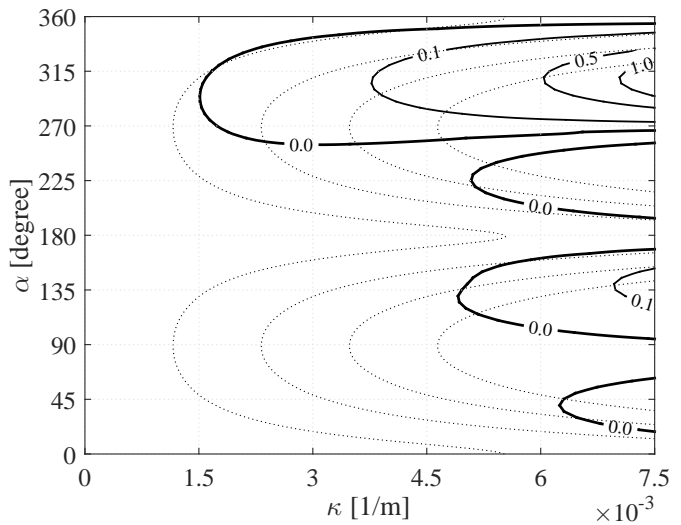

(a) $G_{t o t} / G_{e q} \mathrm{TE}$

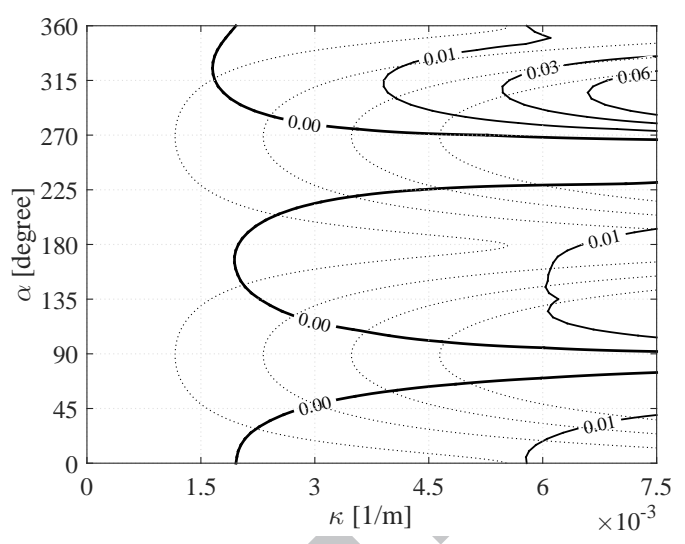

(c) $G_{t o t} / G_{e q} \mathrm{CTS}$

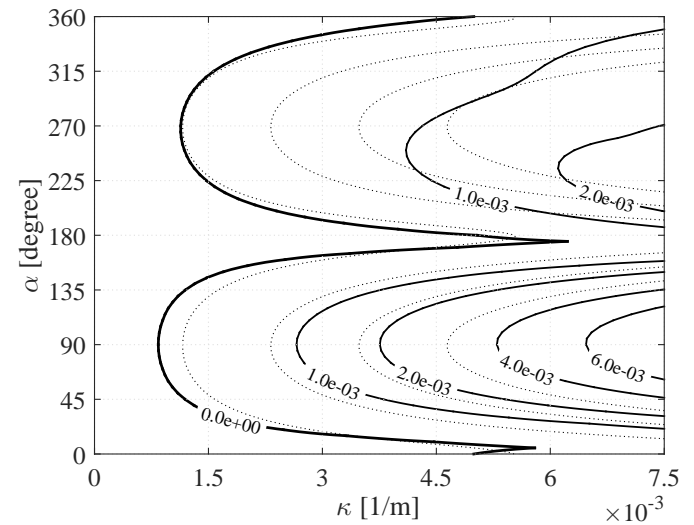

(b) $G_{t o t} / G_{e q} \mathrm{LE}$

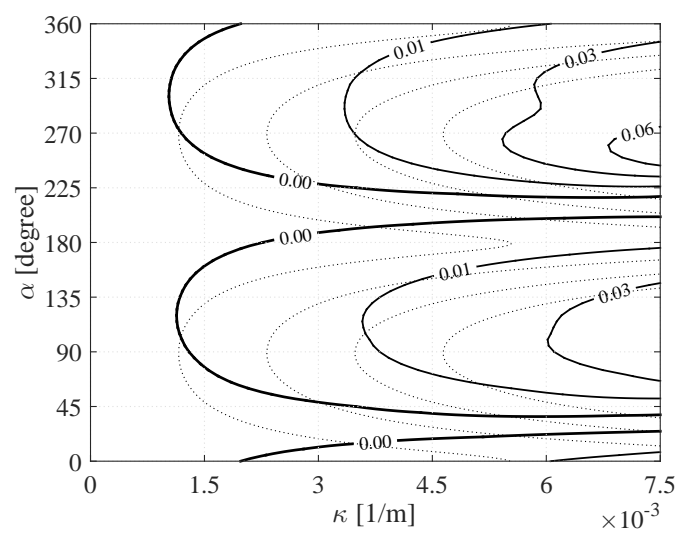

(d) $G_{t o t} / G_{e q}$ CLS

Figure 12: Normalised ERR contour plots of all joints.

Figure 13 shows the critical angle $\beta_{\text {crit }}$ sectors for the four main joints as listed in Tab. 4. It can be seen that the sectors representing the angular direction of the ridges of the $G_{t o t} / G_{e q}$ contours for the TE-joint and the LE-joint are rather narrow. Furthermore, the critical sector of the TE-joint coincides with the CTS-joint, whereas that of the LE-joint coincides with the CLS-joint. Figure 14 (a) and (b) show sections of the normalised ERR contour plots $G_{t o t} / G_{e q}$ evaluated for their critical angles as determined by the peaks of the normalised ERRs shown in Fig. 12.

The critical angles of the mode-mixity were obtained for two levels of bending curvature $\kappa=3 \times 10^{-3} \mathrm{~m}^{-1}$ and $\kappa=6 \times 10^{-3} \mathrm{~m}^{-1}$. The ERRs follow a fourth 


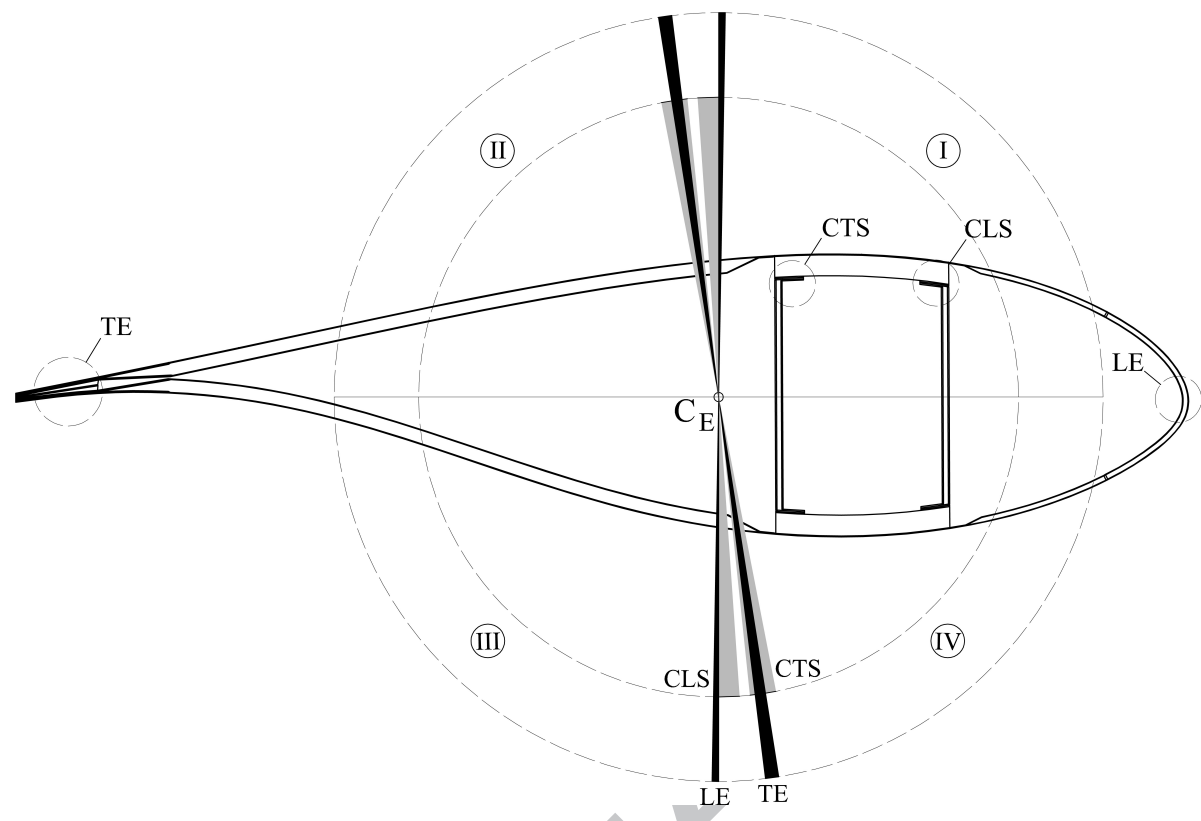

Figure 13: Critical bending moment vector direction angle sectors $\beta_{\text {crit }}$ for the TE-joint (black hatch), the LE-joint (black hatch), the CTS-joint (grey hatch) and the CLS-joint (grey hatch). The hatched sectors are shown for the critical directions $\pm 180^{\circ}$ taking into consideration the angular return period of the ridges in the $G_{t o t} / G_{e q}$ contour plots. The four quadrants are denoted by Roman numerals.

order parabola as a function of the bending curvature.

Figure 15 shows the mode-mixity $\psi_{0}$ evaluated for the critical angles. The trend of the mode-mixity, especially for the CLS-joint depends on the evaluation point of the critical angle since the ridges in some cases are skewed to the abscissa. 


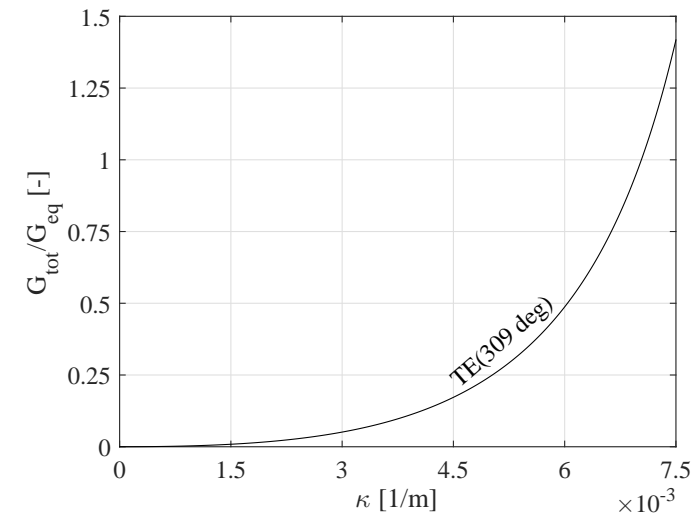

(a)

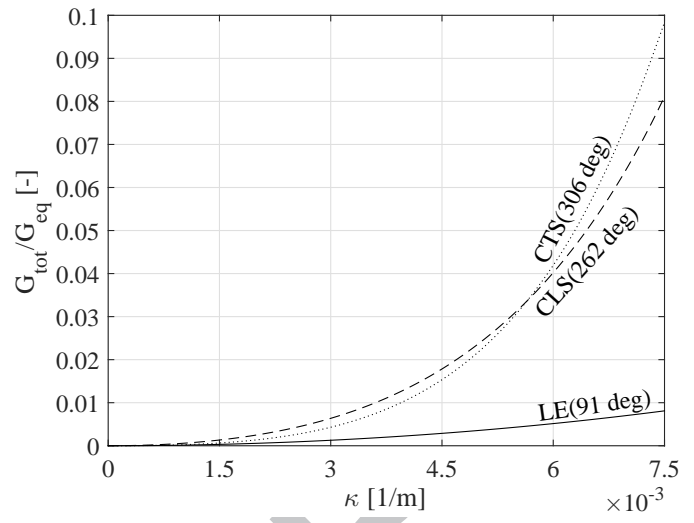

(b)

Figure 14: (a) Utilisation level of the ERR for the TE-joint at its critical direction; (b) Utilisation level of the ERR for the other joints evaluated at their critical directions as indicated next to the graphs.

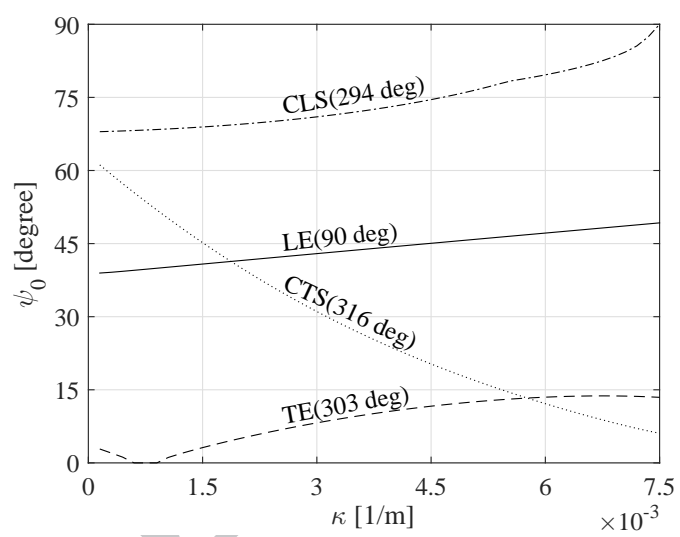

(a)

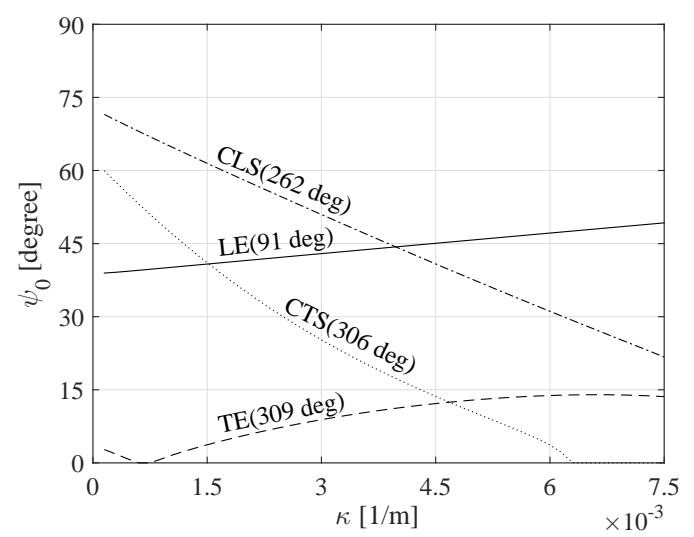

(b)

Figure 15: (a) Mode-mixity of four adhesive joints with critical angles $\alpha_{\text {crit }}$ evaluated for $\kappa=3 \times 10^{-3} \mathrm{~m}^{-1}$. (b) Mode-mixity of four adhesive joints with critical angles $\alpha_{\text {crit }}$ evaluated for $\kappa=6 \times 10^{-3} \mathrm{~m}^{-1}$.

\section{Discussion}

The $K_{I}$ contour plot shown in Fig. 7 (a) is in good agreement with the analytically obtained stress intensity-factor contour plots presented in [12, 
Fig. 8 (a)]. Hence equation 18 in [12] explains the oscillatory occurrence of the ridges every $90^{\circ}$. In Fig. 7 (a) the ERRs are zero when the trailing edge crack faces are under compression due to the contact conditions which excludes every second analytically predicted Mode-I ridge. Conversely, all four ridges occur in Mode-II irrespective of crack face contact as shown in Fig. 7 (b).

Figure 12 (a) shows that the critical angles for the TE-joint leading to opening effects are within the second and fourth quadrant. This is consistent with measurements performed during blade tests with similar loading directions as presented in $[10,11]$. It is remarkable that the TE-opening modes consistently occur within almost the same loading directions in different cases. From this it can be inferred that the critical loading directions for the TE-joint are mainly a function of the airfoil geometry rather than the material stiffness distribution. The latter apparently influences the magnitude of the ERRs but hardly the critical direction. To be more specific, the numerical results of this study corroborate the analytical results which suggest that the severity of the ERRs in the TE-joint is proportional to the curvature (i.e. camber) of the trailing edge panels.

Figure 12 (b) shows that two ridges follow the iso-moment contours, which means that the normalised ERRs are approximately constant for constant bending moments. Figures $12 \mathrm{c}$ ) and d) show two ridges which are about $180^{\circ}$ apart. The return period of the ERR maxima in all investigated joints are multiples of $90^{\circ}$.

Figure 11 (a) is qualitatively similar to the deformation pattern shown in [12, Fig. 10 (a)]. Figure 11 (b) shows that the rhombic deformation pattern of the box-girder affects the diametrically opposed joints in a similar way. From this deformation pattern it can be inferred that both the in-plane bending stiffness of the shear web and the rotational stiffness of the adhesive connection at the cap joint can significantly influence the ERR magnitude.

Figure 13 shows that the critical loading directions for all joints are located within a rather small sector. If this is a typical feature of wind turbine blade cross sections, fracture relevant design load cases obtained from aeroelastic simulations can easily be identified.

Figure 15 (a) and (b) suggest a strong dependence of the mode-mixity on the cross-section curvature i.e. the load magnitude. A distinct Mode-I pre- 
dominance of the TE-joint with $\psi_{0}<15^{\circ}$ can be inferred from both figures. The LE-joint appears to be mainly in the range of an intermediate mode-mix of $\psi_{0} \approx 45^{\circ}$. The mode-mix of the CTS-joint decreases with increasing load from a Mode-II dominated regime to one governed by Mode-I. The CLS-joint is the least predictable, as its trend is not as consistent as the other joints.

Generally speaking, the ERR magnitudes in all joints are rather low $\left(G_{t o t} / G_{e q} \ll 1\right)$ unless the cross-section is subject to excessive loads. In the case of the most severe joint - the trailing edge - Fig.14) (a) shows that a curvature of approx. $\kappa=7 \times 10^{-3} \mathrm{~m}^{-1}$ is required to reach $G_{t o t} / G_{e q}=1$. On the other hand, the iso-moment lines shown in Fig. 7 demonstrate that a bending moment magnitude of $140 \%$ of the flap-wise cross-section capacity is be necessary to reach this curvature. From this it can be inferred that fracture in adhesive joints of blades is hardly related to static crack growth, but most likely driven by fatigue - provided that local buckling is suppressed. Note that the influence of Mode-III was not dealt with in this paper. On the other hand, the shear force and torsional moment magnitude - both of which contribute strongly to Mode-III as described in [22] - are considered to be low in the investigated cross-section, as they are far from the root. Nevertheless, future fracture analyses of adhesive joints should include the effects of shear and torsion.

\section{Conclusion}

The following can be concluded from this study:

i The slice modelling approach presented in this paper allows computationally efficient preliminary geometrically non-linear fracture analyses of adhesive joints in wind turbine blades when compared to full-scale 3D models.

ii The effect of geometric non-linearity is highly relevant for adhesive joint design in wind turbine blades.

iii Of all investigated joints, the Mode-I dominated trailing edge seems to be the most critical.

iv The critical loading angle for the trailing edge joint is primarily governed by its cross-section geometry and is less influenced by the material properties. 
v The critical angles representing the $G_{t o t} / G_{e q}$ peaks for all main joints are within a surprisingly small sector of $\Delta \beta_{\text {crit }} \approx 11^{\circ}$ located in the second and fourth quadrants.

vi Determination of critical loading directions can be used to restrict analysis only to relevant load cases of the many defined by the IEC standard [23].

vii Pure flap-wise and edge-wise blade tests as required for certification procedures might not be sufficient when adhesive joint failure is concerned.

\section{Acknowledgement}

The work is supported by the Danish Energy Agency through the 2010 Energy Technology Development and Demonstration Program (EUDP). The supported EUDP project is titled "Experimental Blade Research - Phase 2" and has journal no. 64011-0006. The work is also partially funded by the Danish Research Council through the project DCCSM, and their support is gratefully acknowledged. The authors would like to thank Peter Berring from DTU-Wind Energy for his input and feedback which initiated and advanced the research presented in this paper.

\section{References}

[1] S. Ataya, M. M. Z. Ahmed, Damages of Wind Turbine Blade Trailing Edge: Forms, Location, and Root Causes, Journal of Engineering Failure Analysis 35 (2013) 480-488.

[2] S. Sheng, Report on Wind Turbine Subsystem Reliability - A survey of Various Databases, Tech. rep., NREL/PR-5000-59111 (2013).

[3] P. U. Haselbach, Nonlinear Finite Element Analysis of Delamination Growth in Composite Wind Turbine Blades, Master's thesis, Universität Bremen, Germany (2013).

[4] P. U. Haselbach, R. D. Bitsche, K. Branner, The Effect of Delaminations on Local Buckling in Wind Turbine Blades, Renewable Energy (2015) submitted. 
[5] A. Corre, Experimental Blade Research - phase 2, DTU Wind Energy E-0083, 2015, Ch. 7.4 Trailing edge strength.

[6] T. von Kármán, Über die Formänderung dünnwandiger Rohre, insbesondere federnder Ausgleichrohre, Z. d. Vereines deutscher Ingenieure 45 (1911) 1889-1895.

[7] L. G. Brazier, On the Flexure of Thin Cylindrical Shells and other 'Thin' Sections, Proc. R. Soc. Lond. Ser. A, 116 (1927) 104-114.

[8] L. S. Cecchini, P. M. Weaver, Brazier Effect in Multibay Airfoil Sections, AIAA Journal 43 (10) (2005) 2252-2258.

[9] A. Riccio, Damage Growth in Aerospace Composites, Springer Cham Heidelberg New York Dordrecht London, 2015.

[10] A. Tesauro, M. Eder, M. Nielsen, Measurement of local relative displacements in large structures, J Strain Analysis 35 (2014) 1-14.

[11] J. Shmueli, M. A. Eder, A. Tesauro, A versatile stereo photogrammetry based technique for measuring fracture mode displacements in structures, Precision Engineering 39 (2015) 38-46.

[12] M. A. Eder, R. D. Bitsche, A qualitative analytical investigation of geometrically nonlinear effects in wind turbine blade cross sections, ThinWalled Structures 93 (2015) 1-9.

[13] C. Bak, F. Zahle, R. Bitsche, T. Kim, A. Yde, L. C. Henriksen, A. Natarajan, M. H. Hansen, Description of the DTU 10 MW Reference Wind Turbine, Tech. Rep. DTU Wind Energy Report-I-0092, DTU Wind Energy (2013).

[14] C. Bak, F. Zahle, R. Bitsche, T. Kim, A. Yde, L. C. Henriksen, P. B. Andersen, A. Natarajan, M. H. Hansen, Design and performance of a $10 \mathrm{MW}$ wind turbine, Wind Energy To be accepted.

[15] Dassault Systèmes, Abaqus Analysis User's Manual (2014).

[16] H. Mang, G. Hofstetter, Festigkeitslehre, SpringerWienNewYork, 2000. 
[17] J. Blasques, M. Stolpe, Multi-material topology optimization of laminated composite beam cross sections, Composite Structures 94 (2012) 3278-3289.

[18] P. Krueger, The virtual crack closure technique: History, Approach and Applications, ICASE Report No. 2002-10.

[19] M. Kenane, M. L. Benzeggagh, Mixed-mode delamination fracture toughness of unidirectional glass/epoxy composites under fatigue loading, Composites Science and Technology 57 (1997) 597-605.

[20] M. A. Eder, R. D. Bitsche, Fracture analysis of adhesive joints in wind turbine blades, Wind Energy (2014) 16.

[21] C. Bak, R. D. Bitsche, A. Yde, T. Kim, H. Morten, F. Zahle, M. Gaunaa, J. P. A. Blasques, M. Døssing, H. Wedel, J. Jens, T. Behrens, The 10MW reference wind turbine, Proceedings of EWEA 2012 - European Wind Energy Conference \& Exhibition. EWEA - The European Wind Energy Association.

[22] M. A. Eder, R. D. Bitsche, M. Nielsen, K. Branner, A Practical Approach to Fracture Analysis at the Trailing Edge of Wind Turbine Rotor Blades, Wind Energy (2013) 15.

[23] IEC 61400-1: Wind Turbines - Part 1: Design Requirements (2005). 